\title{
Vascular Access Profile of End Stage Renal Disease Patients on Maintenance Hemodialysis: Experience from a Tertiary Care Center of Bangladesh
}

Md. Mostarshid Billah ${ }^{1 * *}$ Md. Anisur Rahman 2** Muhammad Abdur Rahim ${ }^{3}$, Tufayel Ahmed Chowdhury ${ }^{4}$ Md. Abdul Latif ${ }^{5}$, Mehruba Alam Annana ${ }^{6}$, Wasim Md. Mohsinul Haque ${ }^{7}$, SarwarI qbal ${ }^{8}$, Md. Abul Mansur ${ }^{9}$

\begin{abstract}
:
Background: A well-functioning vascular access (VA) is essential to provide efficient hemodialysis (HD) therapy. There are 3 main types of access: arterio-venous fistula $(A V F)$, arterio-venous graft $(A V G)$ and central venous catheter (temporary or permanent). The aim of our study was to find vascular access profile of ESRD patients on maintenance hemodialysis in a tertiary care hospital.
\end{abstract}

Methods: This cross-sectional study was carried out in the Department of Nephrology and Dialysis of BIRDEM General Hospital, Dhaka, Bangladesh from November to December, 2015. After taking informed consent from the patients, data were collected from face to face interview and record books of the patients.

Results: Total patients were 107, male were 78 (72.9\%) and female were 29 (27.1\%). The mean age was $57.3 \pm 11.4$ (range 32-80) years. Mean duration of CKD was found $5.7 \pm 4.2$ (range 1-20) years. Maximum dialysis duration was 6.5 years with mean of $1.7 \pm 1.3$ years. Near two-thirds $(68.2 \%)$ of the patients were on thrice-weekly dialysis and one-third (31.8\%) were on twice-weekly dialysis. The vascular access at initiation of dialysis was temporary catheter in majority (91.6\%) of study participant and AV fistula in $8.4 \%$ cases. Of temporary catheter one-third (33.7\%) were temporary jugular catheter and two-third (66.3\%) were temporary femoral catheter. Among jugular catheter $9.1 \%$ were left sided catheter and rest (90.9\%) were right sided catheter. Among the femoral catheter $70.8 \%$ and $29.2 \%$ were right and left side respectively. The current vascular access was AV fistula in $90.7 \%$, temporary catheters $4.7 \%$, permanent catheter $3.7 \%$ and AVG $0.9 \%$ in study patients. Of AVF near one third (29.9\%) were radio-cephalic and $70.1 \%$ were brachial (62.6\% brachio-cephalic, 7.5\% brachio-basilic) fistulas. About seventeen percent (16.8\%) patients had AVF failure.

Conclusion: Temporary dialysis catheters were the most common initial vascular access. Less than one-tenth patients started dialysis with AV fistula. More than two-thirds patients were on thrice weekly dialysis. AV fistula was the most common current vascular access with very small number of permanent catheter and AV graft.

\section{Introduction:}

Chronic kidney diseases (CKD) are increasing world-wide. Many CKD patients end up with End stage renal diseases (ESRD) requiring renal replacement therapy including hemodialysis (HD) which requires vascular access (VA). In the past, one of the major problems and causes of failure in HD was lack of good VA. ${ }^{1}$ A well-functioning VA remains the Achilles heel of HD and is essential to provide efficient dialysis therapy. ${ }^{2}$ Chronic maintenance HD requires stable and repetitive access to the vascular compartment in order to deliver high rates of blood flow to the extracorporeal circuit. There are 3 main types of access: native arteriovenous fistula (AVF), arteriovenous graft (AVG) and central venous catheter (temporary or permanent). ${ }^{1}$ VA usage varies widely across countries. To achieve the best possible patient outcomes in $\mathrm{HD}$, it is widely accepted that the optimal VA device is a well-functioning $\mathrm{AVF}^{3}$ Various VA guidelines state clearly that for patients requiring chronic hemodialysis, the preferred type of access is a native AVF. ${ }^{4}$ Once an AVF has become matured and been used for dialysis, the subsequent failure rate is low, with most patients enjoying fistula function for many years. ${ }^{4}$ other hemodialysis access devices such as synthetic AVGs and central venous catheters are known to have more problems with flow, morbidity and increased cost compared with the AVF. Indeed, several recent studies show that there is a gradient of patient mortality risk by access type, with the highest risk observed with temporary central venous catheters, and the lowest risk with AVFs. ${ }^{3}$ Timing of referral is often thought to be critical, as patients referred to renal services earlier in course of diseases have greater opportunities to access education programs, take part in clinical decisions regarding dialysis and transplantation, and start the renal replacement therapy of their choice via an established VA or peritoneal access route or by preemptive transplant ${ }^{5}$

Epidemiological data on VA usage in ESRD patients across countries have shown a considerable variation in patient's VA preference. In particular, patient preference for a catheter varies across countries, with preference ranging from $1 \%$ of HD patients in Japan and $18 \%$ in the United States, to $42 \%$ and $44 \%$ in Belgium and Canada respectively. ${ }^{6}$

Inadequate preparation is associated with starting dialysis using a temporary catheter, which itself is associated with increased morbidity and mortality. Several studies have reported that a proportion of patients who have been known to the renal services for some time before starting dialysis still 
have urgent dialysis initiation through temporary VA. ${ }^{5}$ The aim of our study was to find vascular access profile of ESRD patients on maintenance hemodialysis in a tertiary care hospital.

\section{Methods}

This cross-sectional study was carried out in the Department of Nephrology and Dialysis of BIRDEM General Hospital Dhaka, Bangladesh from November to December, 2015. A total of 107 adult ESRD patients on maintenance HD for more than one month were included in the study. Informed consent was obtained from the patients after full explanation. Patients were interviewed face to face during dialysis session and data collected in a preformed questionnaire. Demographic data like age and sex were noted. Clinical records were reviewed to note down the frequency and duration of dialysis, duration of chronic kidney diseases, duration of dialysis and type vascular access at initiation of dialysis and current vascular access. Data were processed manually and analyzed with the help of statistical package for social sciences (SPSS) Version 20.0. Quantitative data were analyzed by mean and standard deviation. Qualitative data were analyzed as percentage.

\section{Results}

Total numbers of patients were 107, male were $78(72.9 \%)$ and female were $29(27.1 \%)$. The mean age was $57.3 \pm 11.4$ (range 32-80) years. Mean duration of CKD was found $5.7 \pm$ 4.2 (range 1-20) years (Table I).Maximum duration of dialysis

1. Assistant Professor, Department of Nephrology \& Dialysis, BIRDEM General Hospital, Dhaka, Bangladesh

2. Associate Professor, Department of Nephrology \& Dialysis, BIRDEM General Hospital, Dhaka, Bangladesh

3. Associate Professor, Department of Nephrology \& Dialysis, BIRDEM General Hospital, Dhaka, Bangladesh

4. Registrar, Department of Nephrology \& Dialysis, BIRDEM General Hospital, Dhaka, Bangladesh

5. Registrar, Department of Nephrology \& Dialysis, BIRDEM General Hospital, Dhaka, Bangladesh

6. Associate Professor, Department of Nephrology \& Dialysis, BIRDEM General Hospital, Dhaka, Bangladesh

7. Associate Professor, Department of Nephrology \& Dialysis, BIRDEM General Hospital, Dhaka, Bangladesh

8. Professor, Department of Nephrology \& Dialysis, BIRDEM General Hospital, Dhaka, Bangladesh

9. Professor, Department of Nephrology \& Dialysis, BIRDEM General Hospital \& Director, Transplant unit, BADAS, Dhaka, Bangladesh

**First two authors have similar contribution, and both should be regarded as first author

\section{Corresponding Author:}

Dr. Md. Mostarshid Billah

FCPS (Medicine)

Assistant Professor

Department of Nephrology \& Dialysis

BIRDEM General Hospital, Dhaka, Bangladesh

Email: drbillah70@gmail.com was 6.5 years with mean of $1.7 \pm 1.3$ years. Near two-thirds ( $\mathrm{n}$ $=73,68.2 \%)$ patients were on thrice-weekly dialysis and one-third $(n=34,31.8 \%)$ were on twice-weekly dialysis. The vascular access at initiation of dialysis was temporary catheter in $91.6 \%(n=98)$ of study participant and AV fistula in $8.4 \%$ $(n=9)$ of the study participant and none through AV graft or permanent catheter. Of temporary catheter about one-third $(n=33,33.7 \%)$ were temporary jugular catheter and two-third $(\mathrm{n}=65,66.3 \%)$ were temporary femoral catheter. Among jugular catheter $9.1 \%(n=3)$ were left sided and rest $(90.9 \%)$ were right sided catheter. Among the femoral catheter more than seventy percent $(n=46,70.8 \%)$ were through right sided femoral catheter and near thirty percent $(29.2 \%, n=19)$ through left sided femoral catheter (Table III). The current vascular access was native AV fistula in $90.7 \%(n=97)$ of the CKD patients and temporary catheters $4.7 \%$, permanent catheter $3.7 \%$ and AV graft $0.9 \%$ of the CKD patients (Table II). Of AVF near one third (29.9\%) were radio-cephalic and brachial were $70.1 \%$ (62.6\% were brachio-cephalic, $7.5 \%$ were brachio-basilic) fistulas. About seventeen $(16.8 \%, \mathrm{n}=$ 18) of the patients had a history of failure of AV fistula.

\section{Discussion}

This study was aimed to find vascular access profile of 107 ESRD patients on maintenance hemodialysis. In this study mean age was $57.3 \pm 11.4$ years. This result was correlated with Telles CT et al. They reported that mean age of study patients was $53.5( \pm 16.3)$ years $^{7}$ but Perez-Garcia $R$ et al. found in ANSWER study mean age of $65.2( \pm 14.5)$ years. ${ }^{8}$

In this study more than two-third $(68.2 \%)$ of the patients were on thrice-weekly dialysis and $31.2 \%$ were on twice-weekly dialysis which correlated with the findings of Kulkarniet al. who found about $77 \%$ of the patients were on thrice-weekly dialysis and $23 \%$ were on twice-weekly dialysis. ${ }^{9}$ But Perez-Garcia R et al. found in ANSWER study 97\% patient on thrice weekly hemodialysis. ${ }^{8}$ Anoop G et al. found hemodialysis sessions were thrice-weekly in $75 \%$ of the patients, twice-weekly in $21.9 \%$, and four times weekly in $2.7 \%$ of the patients but in our study no patients were on four times weekly dialysis. ${ }^{10}$

In this study, we found the vascular access at initiation of dialysis was temporary catheter in $91.6 \%$ of patients and AV fistula in $8.4 \%$ of the patients which was correlated with findings of Kulkarni MJ et al. who found $90 \%$ of CKD patient initiate dialysis with temporary catheter and only $10 \%$ patient with AV fistula in India. ${ }^{9}$ Anoop G et al. found only in $15.5 \%$ patients dialysis were initiated with AVF, while $84.5 \%$ were initiated with temporary catheters. ${ }^{10}$ Perez-Garcia $\mathrm{R}$ et al. found $16 \%$ patient initiate dialysis through permanent catheter, $30 \%$ with temporary catheter, $51 \%$ with AV fistula, and $2 \%$ with AV graft. $^{8}$ In the present study the current vascular access was native AV fistula in $90.7 \%$ of the cases and temporary catheters $4.7 \%$, permanent catheter $3.7 \%$ and AV graft, in $0.9 \%$ of study participants Kulkarni MJ et al. also found current vascular access was native AV fistula in $87 \%$ of the cases, and the remaining were on temporary catheters. ${ }^{8}$ Of AV fistula near one third (29.9\%) was radial and two-third (70.1\%) were brachial fistula but Anoop G et al. found 34.3\% 
were brachial and $65.7 \%$ were radial fistulas. ${ }^{10}$ About $16.8 \%$ of the patients had a history of failure of AV fistula which were higher than findings of Anoop G et al. who found $12.8 \%$ fistula failure but lower than Kulkarni MJ et al. who found higher rate $(33 \%)$ fistula failure. ${ }^{8}$

\section{Conclusion}

Our study found that temporary dialysis especially right femoral catheters were the most common initial vascular access. Less than one-tenth patients started dialysis with arterio-venous fistula. More than two-thirds patients were on thrice weekly dialysis. Native arterio-venous fistula was the most common current vascular access with very small number of AV graft and permanent catheter.

Conflict of interest: Nothing to declare

Table I: Demography of the study participants $(\mathrm{N}=107)$

\begin{tabular}{ll}
\hline Total patients & 107 \\
Male/Female & $78(72.9 \%) / 29(27.1 \%)$ \\
Duration of HTN & Mean $10.4 \pm 7.9$ years \\
Duration of CKD & Mean $5.7 \pm 4.2$ years \\
Duration of Dialysis & mean $1.7 \pm 1.3$ years \\
\hline
\end{tabular}

Table II: Vascular access at initiation and current vascular access among the study patients $(\mathrm{N}=107)$

\begin{tabular}{lcc}
\hline Vascular access & $\begin{array}{c}\text { On first } \\
\text { dialysis } \\
\mathbf{( \% )}\end{array}$ & $\begin{array}{c}\text { Current } \\
\text { vascular access } \\
\mathbf{( \% )}\end{array}$ \\
\hline Temporary Jugular catheter & $33(30.8 \%)$ & $1(0.9 \%)$ \\
Temporary Femoral catheter & $65(60.7 \%)$ & $4(3.7 \%)$ \\
AV fistula & $9(8.4 \%)$ & $97(90.7 \%)$ \\
AV graft & 0 & $1(0.9 \%)$ \\
Permanent catheter & 0 & $4(3.7 \%)$ \\
\hline
\end{tabular}

Table III : The anatomic location of the temporary catheters $(\mathbf{N}=\mathbf{9 8})$

\begin{tabular}{lccc}
\hline $\begin{array}{l}\text { Anatomic } \\
\text { location }\end{array}$ & $\begin{array}{c}\text { Number and } \\
\text { percentage } \\
\text { of patients }\end{array}$ & Side & $\begin{array}{c}\text { Temporary } \\
\text { catheter } \\
\mathbf{( \% )}\end{array}$ \\
\hline Internal jugular vein & $33(33.7 \%)$ & $\begin{array}{c}\text { Right } \\
\text { Left }\end{array}$ & $\begin{array}{c}30(90.9 \%) \\
3(9.1 \%)\end{array}$ \\
Femoral vein & $65(66.3 \%)$ & $\begin{array}{c}\text { Right } \\
\text { Left }\end{array}$ & $\begin{array}{c}46(70.8 \%) \\
19(29.2 \%)\end{array}$ \\
\hline
\end{tabular}

\section{References:}

1. Vascular Access 2006 Work Group. Clinical practice guidelines for vascular access.Am J Kidney Dis. 2006; 48(1):176-247.

2. Ethier J, Mendelssohn DC, Elder SJ, Hasegawa T, Akizawa T, Akiba $\mathrm{T}$ et al. Vascular access use and outcomes: an international perspective from the Dialysis Outcomes and Practice Patterns Study. Nephrol Dial Transplant.2008; 23:3219-26.

3. Mendelssohn DC, Ethier J, Elder SJ, Saran R, Port FK, Pisoni RL. Haemodialysis vascular access problems in Canada: results from the Dialysis Outcomes and PracticePatterns Study (DOPPS II). Nephrol Dial Transplant.2006; 21:721-28.

4. Feldman HI, Kobrin S, Wasserstein A. Hemodialysis vascular access morbidity. J Am SocNephrol. 1996; 7:523-35.

5. Buck J, Baker R, Cannaby AM, Nicholson S, Peters J, Warwick G. Why do patients known to renal services still undergo urgent dialysis initiation? A cross-sectional survey.Nephrol Dial Transplant.2007; 22:3240-45.

6. Fissell RB, Fuller DS, Morgenstern H, Gillespie BW, Mendelssohn DC, Rayner HC et al. Hemodialysis patient preference for type of vascular access: variation and predictors across countries in the DOPPS. J Vasc Access. 2013; 14(3):264-72.

7. Telles CT, Dobner T, Pomatti G, Fortes VF, Brock F, Bettinelli LA. Socio-demographic, clinical and laboratory profile of patients submitted to hemodialysis, Rev Rene 2014 ; 15(3):420-26.

8. Perez-Garcia R, Martın MaloA, Joan F, Cuevas X, Llados F, Lozano J et al. Baseline characteristics of an incident haemodialysis population in Spain: results from ANSWER--a multicentre, prospective, observational cohort study. Nephrol Dial Transplant. 2008; 24(2):578-88

9. Kulkarni MJ, Jamale T, Hase NK, Jagdish PK, Keskar V, Patil H, Abhijeet $\mathrm{S}$ et al.A Cross-Sectional Study of Dialysis Practice-Patterns in Patients withChronic Kidney Disease on Maintenance Hemodialysis.Saudi J Kidney Dis Transpl 2015; 26(5):1050-56.

10. Anoop G, Malleshappa P, Kishore B. Vascular Access Profile in Maintenance Hemodialysis Patients. Iranian J of Kidney Dis 2014; 8(3):218-24 